\title{
Tongue lipoma in an older male: A case report and literature review of patients with tongue lipoma reported in China
}

\author{
SHU-LAI LU ${ }^{1,2^{*}}$, JIAN-JIN ZHENG ${ }^{2 *}$, HONG WU ${ }^{2}$, TAO LI $^{2}$, GANG DONG ${ }^{2}$, \\ YUN-LONG WANG ${ }^{3}$ and PI-SHAN YANG ${ }^{1,4}$ \\ ${ }^{1}$ Department of Periodontology, School of Stomatology, Shandong University, Jinan, Shandong 250012; \\ ${ }^{2}$ Oral Medical Center of Qingdao Municipal Hospital, Qingdao, Shandong 266001; \\ ${ }^{3}$ Gout Laboratory, The Affiliated Hospital of Qingdao University, Qingdao, Shandong 266003; \\ ${ }^{4}$ Shandong Provincial Key Laboratory of Oral Tissue Regeneration, Shandong University, Jinan, Shandong 250012, P.R. China
}

Received January 12, 2015; Accepted Sepember 25, 2015

DOI: $10.3892 / \mathrm{ol} .2015 .3865$

\begin{abstract}
Lipoma is the most common benign tumor that occurs at any region where adipose tissue is present. However, as the tongue is devoid of adipocyte it is an extremely rare site for a lipoma to develop, particularly in China. The present study reports the presence of a tongue lipoma in a 78-year-old man that measured $2.2 \times 2.0 \times 1.5 \mathrm{~cm}$ and was located on the left ventral region of the tongue. The tumor was completely excised, and subsequent to 4 years of follow-up, there was no recurrence of the lesion. In addition, the present study reviewed the literature concerning tongue lipomas in China and analyzed 18 other cases of patients with tongue lipomas in the past 30 years, between 1 January 1985 and 31 December 2014.
\end{abstract}

\section{Introduction}

A lipoma is a benign tumor composed of mature adipocytes, which is commonly located in soft tissue, including the back, neck, chest wall and face (1). However lipomas are rarely located in the oral cavity, particularly on the tongue, and oral lipomas only comprise 1-4\% of all benign oral lesions (1). Geschickter (2) reported that only 3 out of 460 lipoma cases were located in the oral cavity. Similarly, Hatziotis (3) reported that in a 22-year period between 1945 and 1967, only 28 out of

Correspondence to: Dr Yun-Long Wang, Gout Laboratory, The Affiliated Hospital of Qingdao University, 16 Jiangsu Road, Qingdao, Shandong 266003, P.R. China

E-mail:wylapollo@163.com

Professor Pi-Shan Yang, Department of Periodontology, School of Stomatology, Shandong University, 44-1 West Wen Hua Road, Jinan, Shandong 250012, P.R. China

Email: yangps@sdu.edu.cn

${ }^{*}$ Contributed equally

Key words: lipoma, tongue, benign tumor, oral lipoma
146 oral lipoma cases were tongue lipomas. In China, tongue lipomas are infrequently reported. The current study presents the case of a patient with a tongue lipoma and reports the findings of a review of 18 other cases of tongue lipoma in China.

\section{Case report}

A 78-year-old male was referred to the Oral and Maxillo-facial Surgery Department of Qingdao Municipal Hospital (Qingdao, China) on 22 October 2010, following complaints of a painless tumor on the left ventral region of the tongue that had been slowly growing for 6 months. The patient did not possess a history of other tumors, but did have a history of diabetes, which was well-controlled, and a surgical history of tonsil resection 26 years ago.

Clinical examination of the tumor revealed a painless, soft-tissue tumor that was $2 \times 2 \mathrm{~cm}$ in size with well-defined margins. The tumor was yellow with multiple blood vessels underneath a smooth overlying surface. There was no ulceration, inflammation, numbness or palpable lymphadenopathy (Fig. 1).

Following routine investigations, including blood and urine tests, liver and kidney function tests, electrocardiogram and chest x-ray, the excision surgery was discussed and decided upon. The patient was placed under general anesthesia and a midline, vertical, mucosal incision was made from the crest of the tumor. The tumor was shelled out, with no adhesions to the surrounding structures. Subsequent to surgery, the excised tumor was histopathologically analyzed.

Macroscopically, the lesion consisted of a single tumor that was globular in shape, measured $2.2 \times 2.0 \times 1.5 \mathrm{~cm}$ and was well-encapsulated, with a thin overlying mucosa. The lesion appeared yellow in color and the surgically cut surface exhibited fatty tissue (Fig. 2).

Microscopic examination revealed that the lesion consisted of mature adipocytes with nuclei located in the periphery. The adipocytes were arranged in lobules and were separated by a thin, fibrous connective tissue. The histopathological diagnosis was classical lipoma (Fig. 3).

A week later, the wound where the tumor had been excised had healed well (Fig. 4) and the stitches were taken out in the clinic. The patient was followed-up over 4 years, during 




Figure 1. Tumor is located at the left ventral region of the tongue.

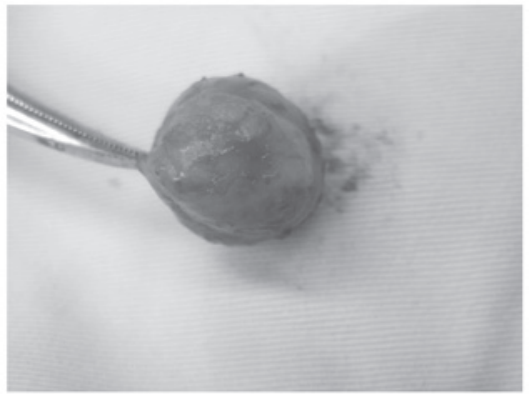

Figure 2. Excised tumor appeared globular in shape and was encapsulated with a thin overlying mucosa.

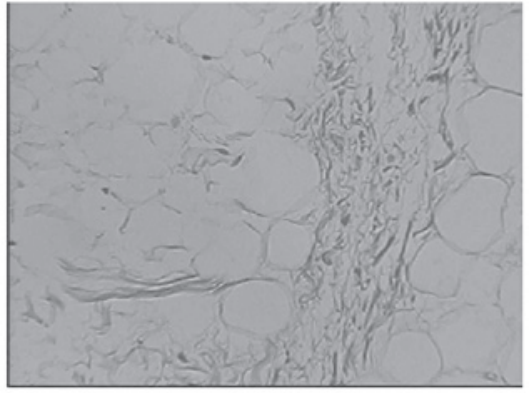

Figure 3. Microscopic examination revealed mature adipocytes arranged in lobules and separated by thin fibrous connective tissue. The histopathological diagnosis was lipoma.



Figure 4. A week subsequent to the excision of the tumor, the wound had healed well and the stitches were removed.

which time there was no recurrence of the tumor. The patient succumbed to liver disease on 17 October 2014.

In total, 4 literature databases were used: Chinese Academic Journals Full-Text, Wanfang, China Science and Technology
Journals were searched with the keywords lipoma and tongue; and PubMed was searched with the keywords lipoma, tongue and China. These searches were used to review the literature concerning tongue lipoma occurrence in China over a 30-year period between 1 January 1985 and 31 December 2014. Overall, 18 cases met the search criteria, including tongue lipomas and its variants, which was confirmed in the studies by histopathological examination. These cases were reported in 16 studies, 1 of which reported 3 cases. The clinical features of all cases are reported in Table I (4-19).

\section{Discussion}

The first description of oral lipoma was provided by Roux in 1848, in a review of alveolar masses (20). Oral lipomas may occur on the major salivary glands, buccal mucosa, lip, palate, vestibule, floor of the mouth and tongue (21). Tongue lipomas are relatively rare and usually arise in the superficial submucosal connective tissue (22). The present study compared the characteristics of 18 cases of tongue lipoma reported in China over a 30 -year period. The findings are as follows:

Juliasse et al (23) reported that oral lipomas were more common among women, and in the Brazilian population the female to male ratio was 2.4:1.0. By contrast, Taira et al (24) reported that the female to male ratio was 1.0:1.7 in Japan, demonstrating a male predilection. Fregnani et al (25) did not observe a gender imbalance. In the present study, the 18 cases of tongue lipoma possessed a female of male ratio was 1:1, demonstrating an equal gender predilection (Fig. 5).

Oral lipomas have been observed in all ages, but in certain studies they have been reported to appear more frequently in adults $>40$ years of age. In the current study, tongue lipomas affected patients between the ages of 1 and 66 years. However, there were no cases reported between the ages of 1 and 30 years (Fig. 6). Tongue lipomas appear to occur more frequently in adults over the age of 30 years. Additionally, Juliasse et al (23) and Taira et al (24) reported that the peak incidence was between the sixth and seventh decade of life. Similar results were obtained in the present study.

Certain studies revealed that lipomas commonly possess a mean diameter of $2.1 \mathrm{~cm}$, with a range of $0.5-10 \mathrm{~cm}(23,26)$. In the present study, the diameter of 11 lipomas was $<2 \mathrm{~cm}$ and 6 lipomas possessed a diameter $\geq 2 \mathrm{~cm}$, with the largest tumor size of $6.0 \times 6.0 \times 5.0 \mathrm{~cm}$. In the 18 cases, tongue lipomas developed at the tip, root, central, lateral and ventral region of the tongue. The lateral region is the most common location for tongue lipoma development in China (Fig. 7).

Histopathologically benign lipomas are classified as: Lipoma or classical lipoma; lipoma variants, including angiolipoma, angiomyolipoma, myolipoma, fibrolipoma, chondroid lipoma, chondrolipoma, osteolipoma, intramuscular lipoma, myelolipoma, sialolipoma and spindle cell/pleomorphic lipoma; hemartomatous lesions; diffuse lipomatous proliferations; and hibernoma (21-23). Lipomas may be encapsulated, non-encapsulated or infiltrating (21). In the present study, 12 cases were classified as lipoma (66.67\%), 3 cases as invasive lipoma (intramuscular lipoma; 16.67\%), 2 cases as atypical lipoma $(11.11 \%)$ and 1 case as chondroid lipoma (5.56\%) (Fig. 8). Classical lipoma is the most common 
Table I. Clinical features of reported patients with tongue lipoma in China between 1985 and 2014.

\begin{tabular}{|c|c|c|c|c|c|c|c|}
\hline $\begin{array}{l}\text { Case } \\
\text { no. }\end{array}$ & First author, year (ref.) & Gender & Age & Location & Duration & Size, $\mathrm{cm}$ & $\begin{array}{c}\text { Histological } \\
\text { diagnosis }\end{array}$ \\
\hline 1 & Ma et al, 1985 (4) & $\mathrm{F}$ & $54 \mathrm{y}$ & Ventral & $1 \mathrm{w}$ & $1.5 \times 1.5 \times 0.7$ & Lipoma \\
\hline 2 & Zhou et al, 1989 (5) & M & $63 \mathrm{y}$ & Tip & $7 \mathrm{y}$ & $6.0 \times 6.0 \times 5.0$ & Lipoma \\
\hline 3 & Dai et al, 1990 (6) & $\mathrm{F}$ & $60 y$ & Root & $2 \mathrm{w}$ & $1.0 \times 0.5 \times 0.5$ & Lipoma \\
\hline 4 & Wang, 1991 (7) & M & $57 \mathrm{y}$ & Tip & $1 \mathrm{y}$ & $2.0 \times 1.5 \times 1.0$ & Lipoma \\
\hline 5 & Lv, 1991 (8) & M & $8 \mathrm{~m}$ & Lateral, multi & $8 \mathrm{~m}$ & $0.6 \times 0.6$ & Lipoma \\
\hline 6 & Ling et al, 1992 (9) & $\mathrm{F}$ & $63 \mathrm{y}$ & Central & $3 \mathrm{~m}$ & not reported & Invasive lipoma \\
\hline 7 & Ling et al, 1992 (9) & M & $58 \mathrm{y}$ & Root & $5 \mathrm{~m}$ & $3.0 \times 3.0 \times 2.0$ & Invasive lipoma \\
\hline 8 & Ling et al, 1992 (9) & $\mathrm{F}$ & $4 \mathrm{~m}$ & Tip, multi & $4 \mathrm{~m}$ & $1.5 \times 1.0 \times 1.0$ & Invasive lipoma \\
\hline 9 & Fang, 1992 (10) & $\mathrm{F}$ & $66 \mathrm{y}$ & Lateral & $8 \mathrm{~m}$ & $1.5 \times 1.0$ & Lipoma \\
\hline 10 & Xie et al, 1995 (11) & $\mathrm{F}$ & $32 \mathrm{y}$ & Tip & $3 y$ & $2.0 \times 1.3 \times 1.2$ & Lipoma \\
\hline 11 & Wang et al, 1996 (12) & $\mathrm{F}$ & $36 y$ & Lateral & $1 \mathrm{y}$ & $0.5 \times 0.6$ & Lipoma \\
\hline 12 & Weng, 1997 (13) & M & $46 y$ & Central & $1 \mathrm{y}$ & $1.5 \times 1.5 \times 1.0$ & Lipoma \\
\hline 13 & Fan, 1998 (14) & $\mathrm{F}$ & $63 \mathrm{y}$ & Lateral & $2 \mathrm{~m}$ & $1.0 \times 1.0 \times 1.0$ & Lipoma \\
\hline 14 & Shi et al, 2004 (15) & M & $40 \mathrm{y}$ & Lateral & $1 \mathrm{w}$ & $1.5 \times 1.2 \times 1.0$ & Atypical lipoma \\
\hline 15 & Chung et al, 2007 (16) & M & $62 \mathrm{y}$ & Lateral & $2 y$ & $6.0 \times 4.0 \times 4.0$ & Lipoma \\
\hline 16 & Shi et al, 2009 (17) & M & $54 \mathrm{y}$ & Root & $45 \mathrm{y}$ & $4.0 \times 3.0 \times 3.0$ & Lipoma \\
\hline 17 & Qin et al, 2012 (18) & $\mathrm{F}$ & $36 y$ & Lateral & $1 \mathrm{y}$ & $1.0 \times 1.0 \times 0.5$ & Chondroid lipoma \\
\hline 18 & Xin et al, 2014 (19) & M & $57 \mathrm{y}$ & Tip & $6 \mathrm{~m}$ & $1.0 \times 1.0 \times 1.0$ & Atypical lipoma \\
\hline
\end{tabular}

w, weeks; m, months; y, years; multi, multiple.

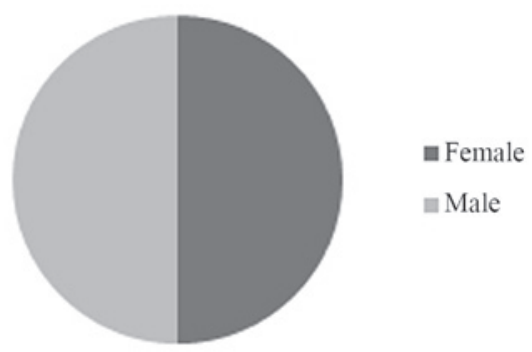

Figure 5. Tongue lipoma gender predilection, as reported in the 18 reviewed cases.

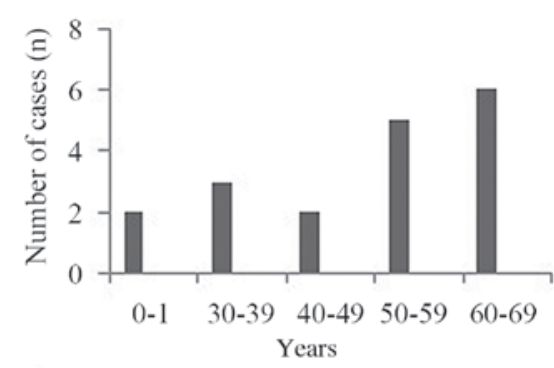

Figure 6. Tongue lipoma age predilection, as reported in the 18 reviewed cases.

type of benign lipoma. The 78-year-old patient in the present study possessed a classical lipoma.

Tongue lipoma may present as solitary or multiple lesions, such as hereditary multiple lipomatosis or Gardner's syndrome $(22,26)$. In infants it appears that multiple lesions

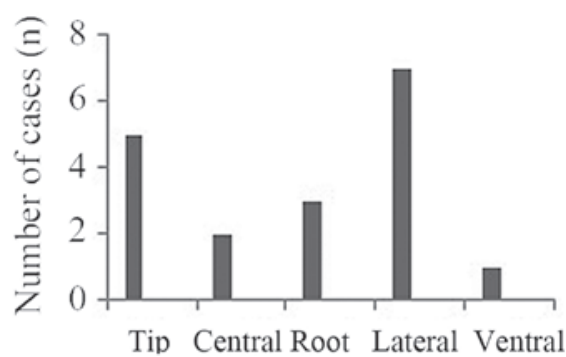

Figure 7. Lipoma location on the tongue, as reported in the 18 reviewed cases.

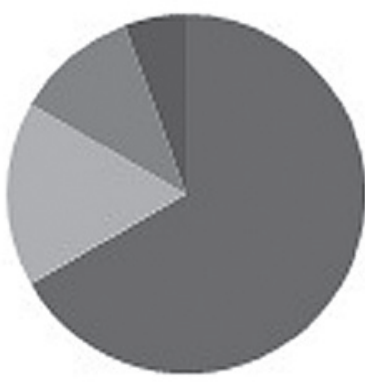

घLipoma $66.67 \%$

$\square$ Invasive lipoma $16.67 \%$

atypical lipoma $11.11 \%$

घChondroid lipoma $5.55 \%$

Figure 8. Histological classification of tongue lipoma, as reported in the 18 reviewed cases.

occur; Berger et al (27) reported 4 lipomas on the tongue of a 9-day-old infant affected with an orofacial-digital syndrome.

In the present study, 2 cases out of 18 were infants presenting with multiple lesions that were located when they were born. The remaining 16 cases were solitary lesions and occurred in adults. 
Generally, lipomas grow slowly and are asymptomatic in the majority of cases. Therefore, the tumor may exist for long time prior to the patient becoming aware of it. The mean duration for tongue lipoma presence has been reported as 3.2 years, with a range between 15 days to 50 years $(26,28)$. The true duration of oral lipoma may be much longer, with the exception of congenital multiple lesions cases, which are revealed when the infants are born. In the present study, the lipoma duration time in 14 patients was $<1$ year, with a shortest duration time of 1 week. In the other 4 cases, the lipoma duration time was $>1$ year with a longest duration time of 45 years.

The etiology of lipomas is unknown; however, possible etiologies consist of a lipoblastic embryonic cell nest origin, metaphase of muscle cells, fatty degeneration, genetics, hormones, trauma, infection, chronicirritation and infarction (22). Certain studies suggest that trauma may trigger proliferation of fatty tissue and cause a lipoma (29), but Carlier (30) and Hatziotis (3) hypothesized that trauma contributes to a patient locating a pre-existing lipoma, rather than causing the tumor.

Histopathological examination yields a definite diagnosis. For deep-seated lingual lipoma, diagnosis may be assisted by using non-invasive techniques, including ultrasound, computed tomography or magnetic resonance imaging (28). Tongue lipomas should be differentiated from other diseases, including mucocele, hemangioma, lymphangioma, rhabdomyoma, neuroma, neurofibroma, pleomorphic adenoma, adenocarcinoma, fibroma and salivary gland tumor (28).

If the treatment of large tongue lipomas is delayed, orofacial deformities, macroglossia, atrophy of tongue musculature, dental abnormalities (including anterior open-bite, masticatory difficulties and interference with movements of the tongue, as well as airway and speech problems) may occur. In addition, secondary trauma may cause large lipomas to ulcerate $(22,28)$.

Surgical resection is the mainstay of treatment. Well-encapsulated lipomas, including classical lipomas, are easily extirpated without recurrence. Regarding non-encapsulated or infiltrating lipomas, it remains advisable to excise them with a cuff of surrounding normal tissue to prevent recurrence, but surrounding structures must be conserved $(25,26)$.

In summary, although tongue lipomas are rarely observed, the present study suggests that clinical settings should be aware of their existence in order to avoid misdiagnosis or the use of the wrong surgical procedure.

\section{Acknowledgements}

This study was supported by funding from the Qingdao Outstanding Health Professional Development Fund and Qingdao Municipal Science and Technology Commission Major Project (grant no. 11-2-3-2-(7)-nsh).

\section{References}

1. Bandéca MC, de Pádua JM, Nadalin MR, Ozório JE, Silva-Sousa YT and da Cruz Perez DE: Oral soft tissues lipomas: A case series. J Can Dent Assoc 73: 431-434, 2007.

2. Geschickter CF: Lipoid tumors. Am J Cancer 21: 617-641, 1934.
3. Hatziotis JC: Lipoma of the oral cavity. Oral Surg Oral Med Oral Pathol 31: 511-524, 1971.

4. Ma L and Wu XB: One case of tongue lipoma. Chinese Journal of Navy Medicine 2: 77, 1985 (In Chinese).

5. Zhou HF, Li GY and Liu YH: Lipoma of tongue body: A case report. Huaxi Oral Medical Journal: 186, 1989.

6. Dai JX, Li B and Zhou XY: Lipoma of tongue: a case report. Journal of Harbin Medical University: 242, 1990.

7. Wang XL: One case of tongue lipoma. Modern Oral Medical Journal 5: 194, 1991.

8. Lv C: Congenital oral multiple lipoma with right eye inward slanting: A case report. Chinese Journal of Clinical Oncology 18: 77, 1991.

9. Ling JD, Chu ZL, Lu BQ, et al: Clinical Analysis of 6 cases of oral and maxillofacial lipoma. Journal of Bengbu Medical College 17: 150, 1992.

10. Fang XH: Lipoma of tongue body: A case report. Journal of Medical Science Yanbian University 15: 213, 1992.

11. Xie C and Wang SQ: One case of tongue lipoma. Academic Journal of Kunming Medical College: 5, 1995.

12. Wang R, Liang G and Huo C: One case of submucosal tongue lipoma. Xinjiang Medical Journal 26: 179, 1996.

13. Weng QC: One case of tongue lipoma. Fujian Medical Journal 19: 137, 1997.

14. Fan WM: Lipoma of tongue: a case report. Journal of Dental Prevention and Treatment 6: 45, 1998.

15. Shi H, Zhou Y, Lou S and Wu N: Two cases of tongue and epiglottis atypical lipoma and review of literature. Chinese Journal of Clinical and Experimental Pathology 20: 680-683, 2004.

16. Chung JC and Ng RW: A huge tongue lipoma. Otolaryngol Head Neck Surg 137: 830-831, 2007.

17. Shi FP and Chen GF: One case of lipoma at the root of the tongue. The Journal of Practical Medicine 25: 1834, 2009.

18. Qin YL, Zhao Y and Shen XB: A case of chondroid lipoma. Journal of Chengde Medical College 29: 319, 2012.

19. Xin J, Zhao J and Zhang J. A case of atypical lipoma at the tip of the tongue. Journal of Oral Science Research 30: 78, 2014.

20. Roux M: On exostoses: Their character. Am J Dent Sci 9: $133-134,1848$.

21. Raj AA, Shetty PM and Yadav SK: Lipoma of the floor of the mouth: Report of an unusually large lesion. J Maxillofac Oral Surg 13: 328-331, 2014.

22. Srinivasan K, Hariharan N, Parthiban P and Shyamala R: Lipoma of tongue - A rare site for a common tumour. Indian J Otolaryngol Head Neck Surg 59: 83-84, 2007.

23. Juliasse LE, Nonaka CF, Pinto LP, Freitas Rde A and Miguel MC: Lipomas of the oral cavity: Clinical and histopathologic study of 41 cases in a Brazilian population. Eur Arch Otorhinolaryngol 267: 459-465, 2010.

24. Taira Y, Yasukawa K, Yamamori I and Iino M: Oral lipoma extending superiorly from mandibular gingivobuccal fold to gingiva: A case report and analysis of 207 patients with oral lipoma in Japan. Odontology 100: 104-108, 2012.

25. Fregnani ER, Pires FR, Falzoni R, Lopes MA and Vargas PA: Lipomas of the oral cavity: Clinical findings, histological classification and proliferative activity of 46 cases. Int J Oral Maxillofac Surg 32: 49-53, 2003.

26. Chandak S, Pandilwar PK, Chandak T and Mundhada R: Huge lipoma of tongue. Contemp Clin Dent 3: 507-509, 2012.

27. Berger PE, Dambrain R and Peiffer R: Considerations on lipomatosis of the tongue in the framework of orofaciodigital syndrome. Acta Stomatol Belg 64: 207-231, 1967 (In French).

28. Magadum D, Sanadi A, Agrawal JM and Agrawai MS: Classic tongue lipoma: A common tumour at a rare site. BMJ Case Rep 30: 1-4, 2013.

29. de Visscher JG: Lipomas and fibrolipomas of the oral cavity. J Maxillofac Surg 10: 177-181, 1982.

30. Carlier G: Lipoma of the tongue. Revue Stomatol 49: 36-42, 1948 (In French). 